\title{
FERTILIZATION AND DEVELOPMENT IN VIVO OF RABBIT OOCYTES CULTIVATED IN VITRO
}

\author{
J. MOTLÍK AND J. FULKA \\ Department of Genetics, Institute of Animal Physiology and Genetics, \\ Czechoslovak Academy of Sciences, Liběchov, Czechoslovakia
}

(Received 6th February 1974)

Pincus \& Enzmann cultivated rabbit ovarian oocytes in vitro as early as 1935 . In a study of the development of cultivated oocytes transferred to the oviducts of mated females, Chang (1955a) obtained $81 \%$ cleavage. In further experiments, Chang (1955b) evaluated embryonic development after the transplantation of cultivated oocytes and observed positive results with the oocytes isolated for cultivation from the ovaries $6 \mathrm{hr}$ or more after injecting sheep pituitary extract. Thibault \& Gérard (1970) fertilized cultivated oocytes in vitro and described the formation of anomalies in the development of the male pronuclei. The aim of the present study was to determine whether oocytes collected shortly after mating followed by an injection of HCG and then cultivated in vitro would be capable, after fertilization in the oviduct, of normal development in the initial stages, or whether anomalies would again be found in the formation of the male pronuclei.

Twenty-three sexually mature female rabbits of different breeds were used. One group consisted of eleven does in oestrus. In the second group of does, pseudopregnancy was induced with 100 i.u. HCG (Praedyn, Spofa) and superovulation with FSH (Folicotropin, Spofa) according to the method described by Kennelly \& Foote (1965). On the day following the last day's treatment of the second group, all the does in both groups were mated with a fertile male and received an intravenous injection of 100 i.u. HCG. Within 30 min after mating and HCG injection, they were subjected, under ether anaesthesia, to unilateral ovariectomy performed through an incision in the linea alba. The ovary with the greater number of large follicles was always removed and oocytes were isolated by perforating the wall of large clear-walled follicles with a dissecting needle under a stereomicroscope. A few oocytes served as controls for the stage of nuclear development and the others were cultivated with cumulus cells, as drops, in $0.1 \mathrm{ml}$ medium under paraffin oil, at $38^{\circ} \mathrm{C}$ in $5 \% \mathrm{CO}_{2}$ in air (Motlik, 1972). The composition of the culture medium ( $\mathrm{pH} \mathrm{7.8)} \mathrm{was}$ as follows : isotonic TC 199 solution (USOL, Prague), $72 \mathrm{ml} ; 1.45 \% \mathrm{NaHCO}_{3}$ $+0.002 \%$ phenol red, $18 \mathrm{ml} ; 5.5 \%$ glucose solution, $10 \mathrm{ml}$; sodium pyruvate, $0.004 \mathrm{~g}$; freeze-dried calf serum growth proteins (USOL, Prague), $30 \mathrm{mg} / \mathrm{ml}$; penicillin, 50 i.u./ml; streptomycin, 50 i.u. $/ \mathrm{ml}$.

According to the results of previous experiments (J. Motlík and J. Fulka, unpublished results), more than $90 \%$ of the oocytes, under the above conditions, 
mature in $9 \frac{1}{2}$ to $10 \mathrm{hr}$ to the metaphase II stage, with the first polar body. After cultivation for $9 \frac{1}{2}$ to $10 \mathrm{hr}$, the oocytes were transplanted into the ampullae of the oviducts on the ovariectomized side. The oocytes of the other ovary served, after ovulation, as the controls for fertilization and the first stages of development. The females were killed 8 to $10 \mathrm{hr}$ after transplantation and the eggs were flushed from both oviducts, fixed in acetalcohol, stained with orcein and examined in a phase-contrast microscope. Eggs clearly showing two polar bodies and two pronuclei, with a tail near one of them, were evaluated as normally fertilized.

The results given in Table 1 show that penetration of spermatozoa into the cytoplasm occurred in $80.4 \%$ of cultivated oocytes from untreated females and in $80.8 \%$ following superovulation. Development of both pronuclei (Pl. 1, Fig. 1) was normal in $60.8 \%$ of the eggs in the former group and in $51.8 \%$ in the latter. There were no significant differences between the two groups in the proportion of eggs with abnormal development of the male pronucleus $(17.6 \%$ and $22.7 \%)$. The frequency of polyspermic eggs was somewhat higher following superovulation. Anomalies that do not occur under normal maturation conditions are interesting from consideration of the suitability of the cultivation technique. Transformation of the sperm head into a male pronucleus was limited to simple swelling or to distribution into one or several clearly staining chromatin structures. The latter were either localized at random in the cytoplasm (Pl. 1, Fig. 2) or, more often, near the normally developing female pronucleus (Pl. 1, Fig. 3). The presence of a tail in the vicinity, allowing definite identification of the male chromatin, was characteristic for these structures (Pl. 1, Fig. 2 and inset in Fig. 3).

Similar anomalies have already been described in cold-activated rabbit ova (Chalmel, 1962). Iwamatsu \& Chang (1972) observed inability of the sperm head to transform to a male pronucleus in the egg cytoplasm of mouse oocytes penetrated by spermatozoa before reaching metaphase I. An incidence of similar post-fertilization anomalies was also very common in pig eggs cultivated from the germinal vesicle stage (Motlík \& Fulka, 1974). Thibault \& Gérard (1970) observed them almost solely in rabbit oocytes isolated for cultivation from large preovulatory follicles and then fertilized in vitro. Later, Thibault (1972) found that if the interval between HCG administration and isolation of the oocytes for cultivation was prolonged to $7 \mathrm{hr}$, the incidence of anomalies

\section{EXPLANATION OF PLATE 1}

All figures are phase-contrast photomicrographs.

FIG. 1. Cultivated rabbit eggs obtained $10 \mathrm{hr}$ after transplantation. Both pronuclei are normally developed. $\times 500$.

Fig. 2. Rabbit egg obtained $8 \mathrm{hr}$ after transplantation. Female pronucleus (FP) is apparently normal, transformation of sperm head is arrested. Sperm tail (arrow) is clearly visible. $\times 800$.

FIG. 3. Rabbit egg obtained $9 \mathrm{hr}$ after transplantation. Female pronucleus with adjacent sperm head (arrow) and polar bodies (PBS) are visible. $\times 600$.

Inset: the same egg with sperm tail (arrow) in the focal plane. $\times 1000$.

Fig. 4. Control oocyte at the late dictyate stage at the beginning of the cultivation. $\times 500$. 


\section{PLATE 1}

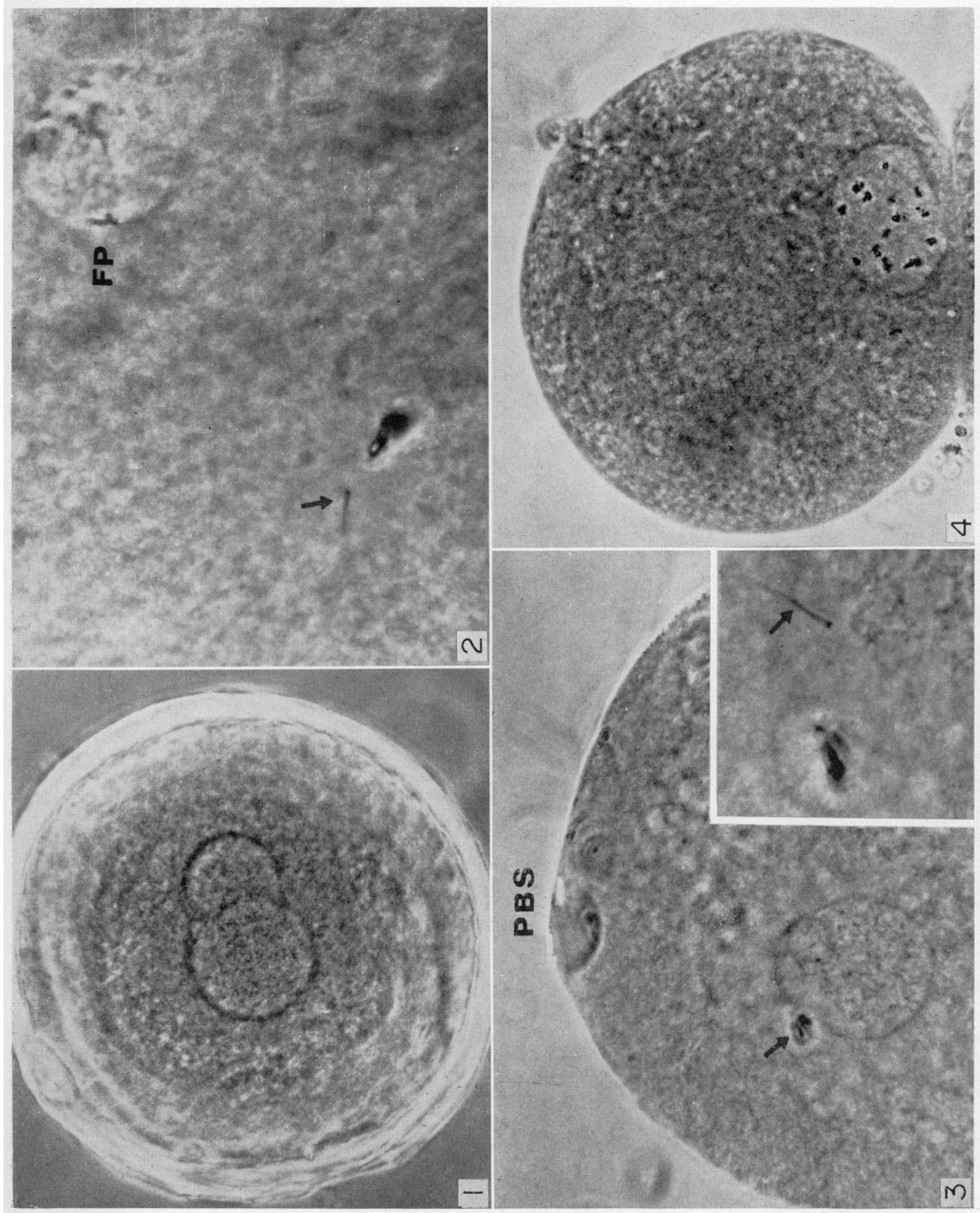

(Facing p. 184) 


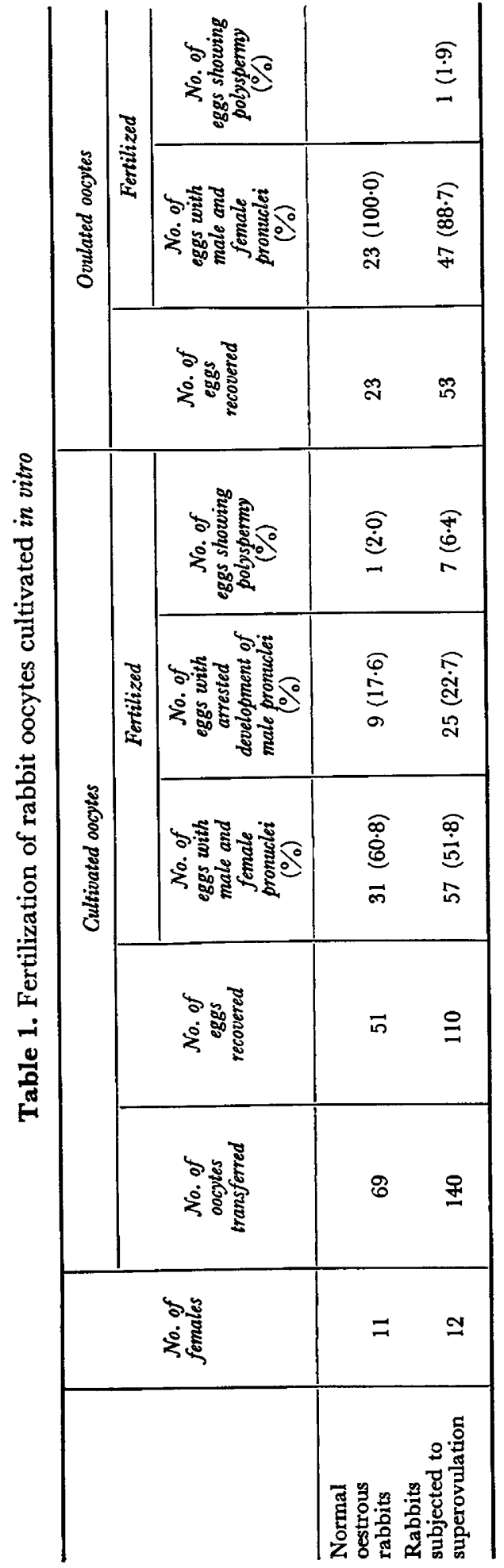


decreased significantly. This observation is in agreement with an earlier finding by Chang (1955b). Thibault (1972) assumed that synthesis of a substance responsible for development of the male pronucleus, which he termed the 'male pronucleus growth factor' (MPGF), did not occur under in-vitro conditions. At $6 \mathrm{hr}$ or more after the administration of HCG or mating, when the nucleus of naturally maturing oocytes reaches metaphase I, a sufficient amount of MPGF does accumulate in the cytoplasm and ensures the development of the male pronucleus. Plate 1, Fig. 4 shows the nuclear stage usual in oocytes at the beginning of cultivation, when the nucleolus is indiscernible, but a distinct nuclear membrane encloses the bivalents characteristic for a late dictyate stage. The interval between mating and hormone injection and fixation of oocytes in acetalcohol did not exceed $30 \mathrm{~min}$. Oocytes obtained from large follicles of untreated rabbits were also at the same stage of the development. Thibault \& Gérard (1970) and Thibault (1972) cultivated oocytes from the same stage of nuclear development and obtained almost $100 \%$ anomalous forms of the male pronuclei but in our experiments two-thirds of the eggs developed normally. These differences could be caused by the composition of the culture medium. Alternatively, after transplantation of cultivated oocytes into the oviduct, complementary maturation could occur and the MPGF in the cytoplasm is then capable of ensuring normal development of both pronuclei.

\section{REFERENGES}

Ghalmel, M.-G. (1962) Possibilité de fécondation des oeufs de Lapine activés parthénogénétiquement. Annls Biol. anim. Biochim. Biophys. 2, 279.

Ghang, M. C. (1955a) The maturation of rabbit oocytes in culture and their maturation, activation, fertilization and subsequent development in the Fallopian tubes. F. exp. Zool. 128, 379.

Ghang, M. C. (1955b) Fertilization and normal development of follicular oocytes in the rabbit. Science, N.Y. 121, 867.

Iwamatsu, T. \& Ghang, M. G. (1972) Sperm penetration in vitro of mouse oocytes at various times during maturation. F. Reprod. Fert. 31, 237.

KenNeLLy, J. J. \& Foote, R. H. (1956) Superovulatory response of pre- and postpubertal rabbits to commercially available gonadotrophins. J. Reprod. Fert. 9, 177.

Motsík, J. (1972) Cultivation of pig oocytes in vitro. Folia biol., Praha, 18, 345.

Morrík, J. \& Fulka, J. (1974) Fertilization of pig oocytes cultivated in vitro. F. Reprod. Fert. 36, 235.

Pincus, G. \& Enzmann, E. V. (1935) The comparative behavior of mammalian eggs in vivo and in vitro. I. The activation of ovarian eggs. J. exp. Med. 62, 665.

Thrbault, G. G. (1972) Final stages of mammalian oocyte maturation. In Oogenesis, pp. 397-411. Eds. J. D. Biggers and A. W. Schuetz. University Park Press, Baltimore,

Thibault, G. \& Gérard, M. (1970) Facteur cytoplasmique nécessaire à la formation du pronucleus mâle dans l'ovocyte de Lapine. C. r. hebd. Séanc. Acad. Sci., Paris, 270, 2025. 